\title{
Research and Exploration on the Educational Reform of Electronic System Design
}

\author{
Hao Liu \\ Beijing Institute of Fashion technology, \\ Beijing, china 100029 \\ gxyliuh@bift.edu.cn
}

Hao ma

Beijing Institute of Fashion technology, Beijing, china 100029

gxymh@bift.edu.cn

\author{
QingChang Meng \\ Beijing Institute of Fashion technology, \\ Beijing, china 100029 \\ gxymengqch@bift.edu.cn \\ Jing-xin Gao \\ Beijing Institute of Fashion technology, \\ Beijing, china 100029 \\ dzhang_qing@163.com
}

\begin{abstract}
Relying on the advantages of the integration of art and technology of BIFT, this paper investigates the effect when we introduce the $\mathrm{CDIO}$ engineering quality education model into teaching and practice. The teaching system of the course focuses on "the cultivation of engineering practice ability, engineering design ability and innovation ability", strive to promote the research-oriented learning method based on the problem, the project and the cases, combined with the discipline competition and various extracurricular activities of science and technology, strengthen the mutual promotion between the professional teaching and the discipline competition, so as to realize the students' ability of electronic system which includes the full development of the theory, practice and engineering.
\end{abstract}

Keyword-teaching research; electronic system design; engineering quality

\section{INTRODUCTION}

With the rapid development of electronic technology, the electronic system is developing towards fast, low power consumption, small volume, lightweight and high level of integration ${ }^{[1]}$. The function of the electronic products is becoming more and more diversified. The traditional design methods can not meet the needs of the modern electronic products, and unprecedented challenges at the same time.

In this new situation, teaching of electronic system design should be according to its position and function in the relevant professional teaching system, master the common knowledge and skill requirements, rational planning of the teaching content, introducing new knowledge and new technology, pay attention to the organic integration of theoretical teaching and practical teaching, curricular and extracurricular practice teaching complement each other, as well as the continuity of the previous follow-up teaching, truly embodies the principle of "efficient, continually strengthened, progressive" cultivation. In order to enhance the students' electronic system design ability and the ability of engineering practice ${ }^{[2]}$.

\section{THE REFORM OBJECTIVES AND THE KEY POINTS OF IMPLEMENTATION}

With the development of science and technology, especially the rapid development of information technology, the demand for the knowledge and skills of the students in the electronic information specialty is in constant change, which requires the professional theory and practical teaching system to adjust with the progress of technology and the needs of the society.

The teaching team of electronic system design has discussed which determine the actual needs of the community as the target, the application of professional skills training as the main line, according to the general requirements which focus on the cultivation of the students' theoretical foundation, practical ability, innovative spirit and comprehensive quality ${ }^{[3]}$. Highlighting the practice teaching system of electronic system, treat the improvements of practice ability, design ability and innovation ability in engineering as the core feature of engineering quality and innovation ability training.

During the implementation process of teaching reform, the teaching team discussed and reached a consensus on the following three points.

A. Engineering ability is a must have "hard skills", rather than "soft power" that is not essential.

Communication and team work require the application and expression of technical knowledge; therefore, technical communication, teamwork, problem solving skills and professional ethics, both of them are engineering skills.

\section{B. pay attention to the improvement of the ability which create opportunities and not just to increase the learning content.}

Adhering to the idea of Constructivism education ambitions, take the students as the main part, construct the students' knowledge system with a marvelous and rich learning 
experience, to achieve the integration training of knowledge and ability, we must create and provide students with opportunities for self-reflection, communication and teamwork. The cultivation of these abilities is the best way through practice, repetition and feedback, other than using the teaching psychology and sociology principles.

\section{Emphasizing foster the integrated ability, instead of attaching a single ability course or skill training.}

Take the whole life cycle as the carrier to organize the curriculum, and establish the relevance of it, through the study and the completion of the project to train the students to acquire knowledge (self-study), application of knowledge (to solve problems), sharing knowledge (team cooperation), found knowledge (technology innovation) and communication skills (Communication), so as to exercise personal and interpersonal skills in practice. Electronic system design ability is the method of application and expression of technical knowledge, engineering ability should be cultivated in such a technology environment.

\section{CONCRETE REFORM MEASURES}

\section{A. Relying on the advantages of the integration of art and technology of our college, CDIO engineering quality education training mode is introduced.}

CDIO engineering education model is the latest

Achievements in international engineering education reform in recent years. It takes the life cycle of engineering product, production process and production system into four stages: conception, design, implementation and operation.

Using the life cycle which from research to development as the carrier, and then make the students in active and practical way to study engineering, and treat strengthen engineering practice ability, engineering design ability and engineering innovation ability as the core.

Electronic system design is a course with very practical, which requires students to acquire both theoretical knowledge, but also have a strong practical ability ${ }^{[4]}$. In the course of teaching, the introduction of CDIO engineering education mode and concept, planning curriculum system and teaching content, strive to promote the research-oriented learning method based on the problem, the project and the cases, strengthen the training of students' innovation ability. Strengthen students' professional knowledge and skills, meanwhile, take the textile and apparel industry as the background. The use of field observation, field teaching and other forms lead students into the field of textile and garment production, learning to master the electronic system design methods and the application of electronic information technology in the textile industry.

In the teaching practice of specific projects, we need pay attention to cultivate students' engineering reasoning and analysis ability as well as the ability to solve practical problems.

- Adhere to the "project oriented" and "task driven" teaching method, in the electronic design related courses, introducing at least one specific design and research project.

- The students are divided into small teams of 4-6 people, each team has a project, and team members complete the entire process from design to manufacture.

- The implementation of the project and the task is to use the means which will make teaching and doing, practice and learning at the same time. During the course, the teachers should teach the necessary skills to students, and then lead to the case as well as the key points and difficult points to be summarized and analyzed, so that the students can expand and develop themselves on this basis.

- No longer treat the "examination" as the unique evaluation method, and in order to avoid high marks but low ability, it will combine the subjective and substantial measures to measure student achievement.

B. Emphasis on the introduction of new technology in teaching, highlighting the method that the design of electronic system has integrated the micro controller and programmable technology, makes a close combination between the electronic system design and electronic product manufacturing, processing, production and other aspects.

With the rapid development of modern electronic technology, the method of electronic system design has been changed greatly ${ }^{[5]}$. Integrate micro controller with the programmable device in a single chip and form a system on chip, which become the development direction of modern electronic system design.

The technology of programmable system on chip and mixed signal chip can be introduced into teaching, reflecting three major changes in electronic system design and application: guide students from functional circuit design to system design, from hardware design to high degree of cooperation design between hardware and software, shift from the application of the traditional integrated circuit to the application of programmable logic device, so as to improve the students' ability of complex electronic system design.

During the course, we should strengthen the use of computer, and then made design, analysis, simulation, and manufacturing, the electronic system design and development and electronic design automation (EDA) technology integrated closely. In the practice teaching process, the use of electronic circuit simulation tools (Multisim, Pspice), circuit board level design tools (Altium Designer), electronic system level simulation tools (Matlab, Simulink), microprocessor system simulation tools (Proteus) and other industry popular design tools can be introduced ${ }^{[6-7]}$. 
C. We need to build a systematic competition and training system through the guiding role of the professional discipline competition on the practical teaching. The students' test information will feedback to the specific teaching practice through the discipline competition, then we can form a virtuous circle pattern which professional teaching and subject competition to promote each other.

Taking the professional discipline competition as the carrier, we treat how to cultivate students' innovative ability, spirit of cooperation, theory with practical learning style, the practical problem of electronic design and production of engineering practice ability as the specific target, feedback the test for the quality of talent to the specific teaching reform through the competition, look forward that will promote the comprehensive quality of the electronic information students who study in our college effectively, and the promotion of quality education process to promote the role of a certain, and will play a certain positive role in the promotion of the quality education.

Hence, we should integrate and optimize the competition training program and curriculum system reform, then improve the existing training model, and establish three levels (stage) of the training system structure at the same time.

- On the basis of theoretical level (theoretical training stage), the training of this level enable students to lay a solid theoretical foundation, and master the basic electronic systems analysis, debugging method.

- Application and practice level (Hands-On Activities stage), the training focus is to improve the students' engineering practice ability and master some basic methods of Electronic Design Automation.

- Comprehensive design level (pre competition reinforcement stage), comprehensive training of students, improve students' ability to begin, comprehensive design ability, scientific research ability.

D. constructing the teaching system of three-dimensional, innovative and practical, to realize the full range of training for the students' electronic system design theory, practice, engineering ability.

It is the key link of the teaching mode reform, through this teaching system; it will realize the full range of training for the students' Comprehensive, practical, engineering ability during the undergraduate course.

- The students' innovative practice can be promoted through the integrated auto adaptive training platform. Adhere to the practice oriented, through improving the incentive system; optimize the practice of environmental measures, to instill practical ideas, to motivate the enthusiasm of the practice, to provide all the conditions for the students to promote their own practice, to enhance students' comprehensive innovation ability.

- We can implement the internal and external integration of innovative practice, building a three-dimensional practical teaching system. In order to meet the needs of the curriculum reform, building the three levels of practical teaching mode which include basic practice, comprehensive practice and innovative practice. the students carry out scientific training plan, discipline competitions and other activities in the form of students' self-organizing academic community, made the extracurricular and curricular practice a mutual promotion, to maximize the practical investment time of students' , training students' comprehensive practical ability.

- We can build a joint laboratory and practice training base with enterprises and enterprises both in China and abroad, and the school will hire outside experts and industry technical personnel to communicate with students, so as to create convenient conditions to engineering quality of students training.

Taking advantage of resources of 985 or 211 colleges and universities in the Beijing area, and strengthen exchanges and cooperation, learning from each other, sharing of resources to achieve quality education.

\section{CONCLUSION}

Teaching reform of electronic system design, based on the original teaching system to highlight training of the students' engineering and practical ability, engineering design ability and engineering innovation ability, through the establishment of systematic and efficient three-dimensional personnel training practice teaching system. It will achieve the students' undergraduate electronic system design theory, practice, engineering ability, this will foster students of design theory, practice, and engineering ability during the whole range of undergraduate stage. Through the reform of the teaching method, the students in our college have achieved good results in recent years. Take the national and Beijing college electronic design competition as an example, recent 3years, the undergraduate students of our college who majored in electronic information engineering and automation, there are 47 students divided into 20 groups to participate in the competition. Students' enthusiasm is very high. Team No.1 3 students were awarded the first prize of Beijing, Team No.57 students were awarded the second prize of Beijing, Team No.6 11 students were awarded the third prize of Beijing, award winning ratio has up to $60 \%$.

\section{ACKNOWLEDGMENT}

The research work was supported by Beijing Institute of Fashion Technology under Grant 2014A-13, PTTBIFT _TD_002, 2014A-27 and RCQJ02140207.

\section{REFERENCE}

[1] Ye Chaohui, Chou, Lin, Zhang Yan. Modern electronic systems SoC Design Innovation Research program [J] Experimental Technology and Management, 2014 (01): 166-168. 
[2] Yu Xiaoping, Tuo Xianguo,XiDai Shun, Gao Song, Liu Mingzhe "Electronic System Design Practice" teachingreform[J] Experiment Science and Technology, 2011 (06): 80-82.

[3] Yu Jian Xing, Xu Bin, Sun Keli, Guo Qiang, Construction and engineering achievements of innovative training model $[\mathrm{J}]$ Chinese university teaching, 2010,32 (1): 28-30.

[4] Wang Jian investigate the electronic system design curriculum system reform [J]Journal of Yangtze University (Natural Science Edition), 2009 (02):377-378.

[5] Cypress.University of New Hampshire Offers Com-puter Architecture Course Focusing on Cypress"'s PSoC Programmable System on Chip. http://www.cypress.com/?rID=48280 . 2011

[6] Ye Zhaohui,Zhou Yongming,Lin Bo,ZhangYan. Research on innovation of Modern Electronic System Design course based on SoC [J].Experimental Technology and Management,2014(01):166-168

[7] Hu Wenlong. On Reform of CDIO-based Engineering Inquiry Teaching Mode[J]. Research in Higher Education of Engineering,2014(01):163168 